\title{
In situ investigation of the cytotoxic and interfacial characteristics of titanium when galvanically coupled with magnesium using scanning electrochemical microscopy
}

Abdelilah Asserghine ${ }^{1,6}$, Amir M. Ashrafi², Atripan Mukherjee ${ }^{2,3}$, Frantisek Petrlak², Zbynek Heger $^{2,3}$, Pavel Svec ${ }^{2}$, Lukas Richtera ${ }^{2,3}$, Livia Nagy ${ }^{1,4}$, Ricardo M. Souto ${ }^{5}$, Geza Nagy ${ }^{1,4}$, Vojtech Adam ${ }^{2,3}$

${ }^{1}$ Department of General and Physical Chemistry, Faculty of Sciences, University of Pecs, 7624, Ifjussg u. 6. Pecs, Hungary

${ }^{2}$ Department of Chemistry and Biochemistry, Mendel University in Brno, Zemedelska 1665/1, 61300 Brno, Czech Republic

${ }^{3}$ Central European Institute of Technology, Brno University of Technology, Purkynova 123, CZ-612 00 Brno, Czech Republic

${ }^{4}$ Janos Szentagothai Research Center, University of Pecs, 7624, Ifjusag u. 20. Pecs, Hungary ${ }^{5}$ Institute of Material Science and Nanotechnology, University of La Laguna, P.O. Box 456, E38200 La Laguna, Tenerife, Canary Islands, Spain

${ }^{6}$ Laboratoire Interfaces et Systemes Electrochimiques (LISE), Sorbonne Universite, CNRS, 4 Place Jussieu, F-75005 Paris, France. 


\begin{abstract}
Recently, the cytotoxic properties of galvanically coupled Mg-Ti particles have been shown to different cells, although this cytotoxic effect has been attributed mainly to Mg due to its tendency to undergo activation when coupled with Ti forming a galvanic cell consisting of an anode (Mg) and a cathode (Ti). However, the role of the Ti cathode has been ignored in explaining the cytotoxic effect of Mg-Ti particles due to its high resistance to corrosion. In this work, the role of titanium (Ti) in the cytotoxic mechanism of galvanically coupled Mg-Ti particles was examined. A model galvanic cell was prepared to simulate the Mg-Ti particles. The electrochemical reactivity of the Ti sample and the $\mathrm{pH}$ change above it due to galvanic coupling with Mg were investigated using scanning electrochemical microscopy (SECM). It was observed that the $\mathrm{Ti}$ surface changed from passive to electrochemically active when coupled with Mg. Furthermore, after only 15 min galvanic coupling with $\mathrm{Mg}$, the $\mathrm{pH}$ in the electrolyte volume adjacent to the Ti surface increased to an alkaline $\mathrm{pH}$ value. The effects of the galvanic coupling of $\mathrm{Ti}$ and $\mathrm{Mg}$, as well as of the alkaline $\mathrm{pH}$ environment, on the viability of Hs27 fibroblast cells were investigated. It was shown that the viability of Hs27 cells significantly diminished when Mg and Ti were galvanically coupled compared to when the two metals were electrically disconnected. Next, the generation of reactive oxygen species (ROS) increased when the Ti and Mg were galvanically coupled. Thus, although Ti usually exhibited high corrosion resistance when exposed to physiological environments, an electrochemically active surface was observed when galvanically coupled with $\mathrm{Mg}$, and this surface may participate in electron transfer reactions with chemical species in the neighboring environment; this participation resulted in the increased $\mathrm{pH}$ values above its surface and enhanced generation of ROS. These features contributed to the development of cytotoxic effects by galvanically coupled Mg-Ti particles.
\end{abstract}

Keywords: titanium; magnesium; galvanic coupling; local electrochemical activity; cytotoxic effects; pH variations; reactive oxygen species. 


\section{Introduction}

In the last few decades, $\mathrm{Ti}$ and $\mathrm{Mg}$ have gained considerable attention in medicine due to their intrinsic physicochemical properties and biocompatibility. Ti-Mg alloys are widely used in biomedicine as implants to supersede damaged tissue or repair its function ${ }^{1-2}$. Recently, galvanically coupled Mg-Ti particles were shown to possess therapeutic properties against infection or even cancer cells. Thus, Kim and Gilbert reported a decrease in cell viability while investigating the viability of MC3T3 cells in the presence of galvanically coupled Mg-Ti particles $^{3}$. Later, these authors also reported the cytotoxic effect of Mg-Ti particles on human osteosarcoma cells, supporting a potential application in cancer therapy ${ }^{4}$. In fact, damage to biological cells in contact with a metal surface may stem from a variety of reasons, including the release of toxic metal cations from corroding metals, the generation of ROS on the metal surface ${ }^{5}$, and the change in local $\mathrm{pH}^{5}$ at the interface. In addition, it has been reported that heterogeneous electron transfer reactions on metals may promote damage in the surrounding biological cells ${ }^{6-7}$. However, the decrease in the cell viability on the galvanically coupled MgTi particles was mainly attributed to the ROS generated from the corrosion of Mg, while Ti would solely enhance the corrosion rates of $\mathrm{Mg}^{3-4}$.

Ti possesses a high corrosion resistance in aqueous and physiological environments due to the adherent and compact passive titanium dioxide $\left(\mathrm{TiO}_{2}\right)$ layer formed on its surface. The $\mathrm{TiO}_{2}$ layer hinders the occurrence of electron transfer reactions with the local environment and reduces the release of metal cations from its surface ${ }^{8-10}$. In a Ti-Mg galvanic cell, Ti acts as the cathode, whereas Mg acts as the anode on the basis of their standard reduction potentials. However, it is suspected that Ti may exhibit cytotoxic characteristics when it is galvanically coupled with Mg. Indeed, even cathodically polarized Ti has been proposed to be effective for periprosthetic joint infections ${ }^{11}$. Therefore, an in situ understanding of the electrochemical behavior of Ti galvanically coupled with $\mathrm{Mg}$ is highly demanded.

In the last decade, scanning electrochemical microscopy (SECM) has been considered to be a powerful in situ tool for characterizing the electrochemical reactivity of a metal surface at the micrometer scale and smaller ${ }^{12-13}$. In particular, it has found application for studying the corrosion of $\mathrm{Mg}$ and its alloys ${ }^{12,14}$. Thus, investigations on electron transfer reactions ${ }^{15}, \mathrm{pH}$ monitoring ${ }^{16}$, detection of hydrogen $\left(\mathrm{H}_{2}\right)$ gas evolution ${ }^{17-20}$, and quantification of $\mathrm{Mg}^{2+}$ release when $\mathrm{Mg}$ is either maintained at its open-circuit potential (OCP) or anodically polarized ${ }^{21-22}$ have been successfully carried out using SECM. In this way, $\mathrm{pH}$ values of approximately 10 have been observed for anodically polarized $\mathrm{Mg}^{16}$. On the other hand, SECM has also been employed to characterize the surface reactivity of $\mathrm{Ti}$ and its alloys ${ }^{12}$, including the 
quantification of heterogeneous electron transfer reactions $\mathrm{s}^{23-24}$ and the monitoring of $\mathrm{pH}$ during the self-healing of the passive film on $\mathrm{Ti}^{8-10}$. In addition, the nucleation of corrosion pits has been visualized on $\mathrm{Ti}^{25}$. However, no systematic study has yet been performed to quantify the rate of the heterogeneous electron transfer reaction and the local $\mathrm{pH}$ near $\mathrm{Ti}$ when it is galvanically coupled with Mg.

This work aims to understand the cytotoxic effect of Ti galvanically coupled with Mg. $\mathrm{Ti}$ and Mg metals were mounted into a resin sleeve and electrically connected on the rear side of the sample to mimic galvanically coupled Mg-Ti particles. The cytotoxic effect was studied on fibroblast cells to represent the surrounding cells near bones where $\mathrm{Ti}$ and $\mathrm{Mg}$ implants would be employed. Fibroblast cells were selected for their prevalence in a variety of connective tissues, such as cartilage. Furthermore, fibroblast cells are very important for integration of biomaterials, positioning them among the most important cell types for the study of biomaterials for regenerative medicine ${ }^{26}$. SECM operated in feedback and potentiometric modes was used to quantify the heterogeneous electron transfer reactions and to monitor the $\mathrm{pH}$ near the Ti galvanically coupled with $\mathrm{Mg}$ with a spatial resolution.

\section{Materials and methods}

\subsection{Materials}

The human cell line used in the experiment (foreskin fibroblasts, Hs27) was purchased from the American Type Culture Collection (ATCC, Manassas, VA, USA). Fetal bovine serum (FBS)-South American origin was obtained from Biosera (Kansas City, MO, USA). Dulbecco’s modified Eagle’s (DMEM) medium-high glucose, penicillin, streptomycin, glutamine, trypsin, $\mathrm{HCl}, \mathrm{NaCl}, \mathrm{KCl}, \mathrm{Na}_{2} \mathrm{HPO}$, $\mathrm{KH}_{2} \mathrm{PO}_{4}$, and ferrocene methanol (FcMeOH) were purchased from Sigma-Aldrich (Saint Louis, MO, USA), and Trypan blue was purchased from Thermo Fisher Scientific (Waltham, MA, USA).

A model galvanic cell (MGC) was prepared by embedding Ti and Mg strips in an epoxy resin to produce a flat surface with the two materials surrounded by an electrical insulator. Ti with a purity of $99.99 \%$ and a surface area of $0.28 \mathrm{~cm}^{2}$ and $\mathrm{Mg}$ with a purity of $99 \%$ and a surface area of $0.23 \mathrm{~cm}^{2}$ were employed, and they were separated by $0.5 \mathrm{~cm}$. For this purpose, the $\mathrm{Ti}$ and Mg strips were first placed in a cylindrical mold that was filled with a mixture of the resin and Epofix hardener (Struers, Denmark) at an 8:1 ratio. The resin was left for $12 \mathrm{~h}$ to harden at room temperature. A smooth and flat surface was obtained by grinding with SiC paper. Further polishing was carried out using alumina slurries at different grain sizes of 1.0, 0.30 , and $0.050 \mu \mathrm{m}$. This was followed by a thorough rinse with acetone and water to remove 
any residue from the polishing step. For the electrochemical experiments, the plastic body of the prepared MGC was wrapped with adhesive tape to produce a small container for the test electrolyte. The opposite ends of the two metal strips were soldered to short-length copper wires either to provide electrical connection to the potentiostat when polarization of the sample was desired or to establish galvanic coupling between the two metals. In the latter case, no electrical connection of the Ti-Mg MGC to the potentiostat was made during the measurement.

\subsection{Electrochemical characterization}

Conventional electrochemical testing was performed using electrochemical impedance spectroscopy (EIS) for the metal samples immersed in a $0.1 \mathrm{M} \mathrm{NaCl}$ solution at room temperature. Prior conditioning of the Ti strip in the MGC was performed by anodization at $+2.00 \mathrm{~V}$ vs. a $\mathrm{Ag} / \mathrm{AgCl} /(3 \mathrm{M}) \mathrm{KCl}$ reference electrode in a deaerated $0.1 \mathrm{M} \mathrm{NaCl}$ solution at ambient temperature for $120 \mathrm{~s}$ to ensure the formation of a passive $\mathrm{TiO}_{2}$ layer on the surface that was reproducible and well characterized ${ }^{27}$ according to the amperometric transient shown in Figure 1. Eventually, a cathodic potential polarization at a controlled voltage could be applied to the Ti strip to simulate the electrical condition corresponding to the mixed galvanic potential of the Ti-Mg galvanic couple. Figure 2 shows the variation of the OCP before and after the galvanic coupling of $\mathrm{Ti}$ to $\mathrm{Mg}$, as well as the mixed galvanic potential attained during the galvanic coupling stage. Approximately 90-100 s are required for the disconnected Ti strip to attain a stable OCP value of ca. $-0.2 \mathrm{~V}$ vs. $\mathrm{Ag} / \mathrm{AgCl} /(3 \mathrm{M} \mathrm{KCl})$ both prior and after finishing the galvanic coupling to $\mathrm{Mg}$, thus indicating the occurrence of a reproducible oxide layer on the surface of the Ti. Upon galvanic coupling to Mg, the potential of the Ti surface is shifted by $0.8-0.9 \mathrm{~V}$ in the negative potential direction as reported by Kim and Gilbert ${ }^{3,4}$. Although a slow shift of the galvanic potential towards more positive potentials was recorded, the variation was sufficiently slow to assign a quasi-stationary potential value to the system for the measurement of an electrochemical impedance spectrum for the characterization of the anodically-polarized Ti strip during galvanic coupling. In this work, cathodic polarization at $-0.8 \mathrm{~V}$ vs. $\mathrm{Ag} / \mathrm{AgCl} /(3 \mathrm{M}) \mathrm{KCl}$ was selected ${ }^{28}$.

EIS measurements were performed using a CHI604E electrochemical workstation supplied by $\mathrm{CH}$ Instruments (Houston, TX, USA). The three-electrode configuration was completed using $\mathrm{Ag} / \mathrm{AgCl} /(3 \mathrm{M}) \mathrm{KCl}$ and platinum wire (diameter: $0.5 \mathrm{~mm}$, length: $20 \mathrm{~mm}$ ) as reference and auxiliary electrodes, respectively. All potential values in this work refer to the $\mathrm{Ag} / \mathrm{AgCl} /(3 \mathrm{M}) \mathrm{KCl}$ reference electrode. The amplitude of the sinusoidal voltage perturbation was $10 \mathrm{mV}$ in the frequency range of $10 \mathrm{kHz}$ to $100 \mathrm{mHz}$. 
The SECM experiments were performed using a Uniscan model 370 (BioLogic, Seyssinet-Pariset, France) combined with a PG580R bipotentiostat (Biologic, SeyssinetPariset, France) as the electrochemical interface. Amperometric operation was ensured with a platinum counter electrode and a carbon microelectrode tip. Potentiometric operation was achieved using a $\mathrm{Sb} / \mathrm{Sb}_{2} \mathrm{O}_{3}$ microelectrode as the $\mathrm{pH}$-sensitive tip and a $\mathrm{Ag} / \mathrm{AgCl} /(3 \mathrm{M}) \mathrm{KCl}$ reference electrode.

The carbon microelectrode used in the SECM experiments was prepared according to the procedure described before ${ }^{29}$. First, a borosilicate capillary was rinsed with acetone and double distilled water. One end of the cleaned capillary was closed by using a Bunsen burner. Afterward, a carbon microfiber (diameter: $30 \mu \mathrm{m}$, and length: 3-5 cm, provided by Specialty Materials, Inc. (Lowell, MA, USA) as a generous gift) was inserted into the capillary from the open end. To prevent the formation of any air bubbles around the fiber during the sealing step, a vacuum pump was connected to the open end of the capillary. The distance and position of the capillary from the electric heating coil was finely adjusted. Approximately half of the fiber was sealed inside the melted capillary by applying an appropriate electric power while the capillary was gently moved downwards. Electric contact was then provided by a copper wire soldered to the carbon fiber. Fine grinding of the sealed part of the capillary using sandpaper (600 grit) was continued until the carbon disk appeared at the center of the capillary tip. The pointed end of the carbon fiber located at the center of the capillary was achieved by fine polishing on a polishing pad (Buehler Ltd., Bluff, IL, USA) loaded with alumina slurries with diameters of $1.0,0.30$, and $0.050 \mu \mathrm{m}$ and subsequently controlled with the assistance of an optical microscope. As a result, a micro disk-type electrode with a ratio between the insulating shield thickness to the disc electrode radius (RG) of 10 was fabricated for use in the SECM measurements.

An antimony microelectrode was prepared using the procedure reported elsewhere ${ }^{30}$. The antimony tip was prepared by melting high purity antimony powder (Sigma-Aldrich, St. Louis, MO, USA) in a pot using a conventional gas burner flame. By using syringe suction, the melted antimony was sucked in a glass capillary (B200-116-10, Sutter Instruments, Novato, CA, USA). The capillary filled with antimony was slowly rotated over a glass blower flame to soften. Then, it was pulled out using metallic tweezers to obtain a capillary with the desired small diameter. The as-prepared antimony tip was inserted in the lumen of another glass capillary (inner diameter at its end: $100 \mu \mathrm{m}$ ) so that the end of the tip was protruding outside (15 $\mu \mathrm{m})$, while the other part (20 $\mu \mathrm{m})$ was inside the capillary. Metal mercury was poured inside the capillary, and a copper wire was inserted in the capillary to provide electrical contact. The 
sealing of both ends was assured with Loctite adhesive. The potential-pH response of this antimony microelectrode was tested with a set of buffers covering the $\mathrm{pH}$ range of 4-10. Linear behavior with $-51 \mathrm{mV}$ decade ${ }^{-1}$ slope was found as shown in Figure 3.

\subsection{Characterization of the cytotoxic effects of galvanically coupled Ti-Mg}

Before each experiment with the fibroblast cells, the MGC containing the Ti and Mg strips was cleaned by grinding with P2000 sandpaper until a reflective corrosion-free surface was obtained. The cleaned surface was then sterilized by soaking in $70 \%$ aqueous ethanol and using UV radiation for $1 \mathrm{~h}$.

Hs27 cells were cultured in DMEM with 2 mM glutamine and 10\% FBS. The media were supplemented with penicillin $\left(100 \mathrm{U} \mathrm{mL}^{-1}\right)$ and streptomycin $\left(0.1 \mathrm{mg} \mathrm{mL}^{-1}\right)$. In the experiments, 100,000 fibroblast cells were placed on a cleaned and sterilized MGC with a surface area of $7.065 \mathrm{~cm}^{2}$ (i.e., 14,155 cells $\mathrm{cm}^{-2}$ ). In all the following experiments, the same amount of Hs27 cells was used, and after seeding on the MGC, the cells were incubated aseptically at $37{ }^{\circ} \mathrm{C}$ in a humidified incubator (Eppendorf, Hamburg, Germany) with $5 \% \mathrm{CO}_{2}$.

After $48 \mathrm{~h}$ of cell proliferation on the MGC, the adherent cells were washed $4 \times$ with phosphate-buffered saline (PBS, pH 7.4) and harvested by trypsinization. Then, the trypsin was inactivated with a medium, and the cells were harvested by centrifugation at $400 \mathrm{~g}$ at $25^{\circ} \mathrm{C}$ for 5 min. Dead cells were stained with Trypan blue, and both the live/dead cell ratio and the average size were determined using a Countess II FL automated cell counter (Thermo Fisher Scientific, Waltham, MA, USA). The experiments were carried out under galvanic coupling conditions where $\mathrm{Ti}$ and $\mathrm{Mg}$ were electrically connected at the rear of the MGC and when the two metals were electrically disconnected (i.e., effectively at their corresponding OCPs in the environment) as the negative control experiment.

After $48 \mathrm{~h}$ of incubation, the measurement of ROS was performed using the CellROX ${ }^{\mathrm{TM}}$ Deep Red flow cytometry assay kit (Thermo Fisher Scientific). CellROX Deep Red was incubated with cells in a medium for $30 \mathrm{~min}$ at $37^{\circ} \mathrm{C}$ and $5 \% \mathrm{CO}_{2}$ in the dark. One microliter of this solution was used to stain $0.5 \mathrm{~mL}$ of the cell suspension for a final concentration of 500 $\mathrm{nM}$. Then, the cells were washed $3 \times$ with PBS (pH 7.4) and centrifuged at $400 \mathrm{~g}$ and $25^{\circ} \mathrm{C}$ for 5 min. Next, the cells were resuspended in 3\% FBS in PBS. The intracellular ROS content was quantified via fluorescence using a $640 \mathrm{~nm}$ laser and $675 \mathrm{~nm}$ filter on a BD Accuri C6 Plus flow cytometer (BD Biosciences, Franklin Lakes, NJ, USA). The flow rate was $35 \mu \mathrm{L} \mathrm{min}{ }^{-1}$, and a minimum of 10,000 cells were analyzed in each group. The determination of ROS content 
in the MGC was carried out under both galvanically coupled and electrically disconnected configurations.

The effect of $\mathrm{pH}$ on cell cultures was investigated as follows. A total of 100,000 cells were seeded in every well of 12-well cell culture plates. In the control sample, the $\mathrm{pH}$ of the medium was maintained at 7.5. Other cell culture wells were maintained with the same number of cells at pH 8 and $\mathrm{pH}$ 9. The $\mathrm{pH}$ was adjusted every $6 \mathrm{~h}$ using a 2.0 $\mathrm{M} \mathrm{NaOH}$ solution for $48 \mathrm{~h}$ and was measured by a pH meter (XS-Instrument, Carpi, Italy). Then, the cells were harvested and stained using Trypan blue, and the number of living and dead cells was counted using a Countess II FL automated cell counter (Thermo Fisher Scientific). In addition, the morphology of cells exposed to culture media at different $\mathrm{pH}$ values was observed using phase contrast microscopy (EVOS FL Auto Cell Imaging System, Thermo Fisher Scientific).

\subsection{SEM/EDS and cryo-SEM analysis}

Images of the metals embedded in the resin were obtained using MIRA 2 SEM (TESCAN Ltd., Brno, Czech Republic). The MGC was attached to the holder and inserted into the SEM. An in-beam secondary electron (SE) detector was used with an accelerating voltage of $15 \mathrm{kV}$. The working distance was set at $3 \mathrm{~mm}$, and ultrahigh resolution was used as the scanning mode. The measurement was performed in high vacuum. Elemental analysis was performed on an X-MAX 50 EDX detector (Oxford Instruments plc, Abingdon, UK) under the same conditions that were used for imaging, only the working distance was changed to $15 \mathrm{~mm}$ and an external SE detector was used. The spot size was $120 \mathrm{~nm}$. SEM images along with EDS analysis confirmed the chemical composition of the embedded metals, and the presence of $\mathrm{Ti}$ and Mg along with oxygen as major components was confirmed (see Figure 4).

The structural changes in the fibroblast cells due to the galvanic coupling of $\mathrm{Ti}$ and $\mathrm{Mg}$ were observed by SEM. To ensure the biocompatibility of MGC, 100,000 Hs27 cells were cultured on an MGC in OCP mode (i.e., without electrical connection). After $48 \mathrm{~h}$ of proliferation, the cells were imaged by SEM (Tescan MAIA 3, Tescan Ltd., Brno, Czech Republic) equipped with a field emission gun at an accelerating voltage of $1 \mathrm{keV}$. Furthermore, for imaging Hs27, a cryogenic system PP3010 (Quorum Technologies Ltd, Sussex, UK) was used. The cells were cultivated on a carbon stub, transferred to a copper holder and frozen in liquid nitrogen. Under vacuum conditions, samples were transferred to an SEM chamber equipped with a cryostage and observed under high vacuum conditions. The images from the cryo-SEM were obtained using an external SE detector in a working distance range of 2.97$3.07 \mathrm{~mm}$ and at an acceleration voltage of $1 \mathrm{kV}$. Images with a resolution of $768 \times 858$ were 
obtained at 860-2,220-fold magnification covering a range of view from 93.4 to $241 \mu \mathrm{m}$. Full frame capture was performed in analytical mode, and the accumulation of images with image shift correction was enabled; this process took approximately 1.5 min with an $\sim 1 \mu \mathrm{s}$ pixel $^{-1}$ dwell time. The spot size was set at $17 \mathrm{~nm}$. Similar results for cell imaging obtained by two different methods confirm the biocompatibility of the constructed MGC when the two metals were electrically disconnected. Accordingly, this allows us to use this methodology to study the effect of galvanic coupling on cell viability.

\section{Results and discussion}

\subsection{Biocompatibility of the $M G C$}

The endurance of Hs27 cells on the MGC surface while the two metals were electrically disconnected was confirmed by using SEM and cryo-SEM. As shown in the cryo-SEM image in Figure 5a, the Hs27 cells overlapped and attached to the carbon stub surface. Similarly, Hs27 cells imaged by SEM under the same conditions were healthy, overlapping each other and remaining attached to the MGC surface, as shown in Figure 5b. This observation confirmed the biocompatible nature of the MGC when it was in OCP mode. Therefore, Hs27 cells in OCP mode were regarded as the negative control in subsequent cell culture experiments.

In addition, a Trypan blue exclusion assay was used to monitor the viability of Hs27 under the defined conditions. The live/dead report obtained from the assay shows $97 \%$ survivability of Hs27 under non-galvanic coupling (OCP) conditions, where the average live and dead cell sizes were $13.53 \mu \mathrm{m}$ and $15.00 \mu \mathrm{m}$, respectively (further details are shown in Figure 6a). Moreover, under galvanic conditions, $43 \%$ of cells were found to have survived with average live and dead cell sizes of $7.00 \mu \mathrm{m}$ and $7.24 \mu \mathrm{m}$, respectively (see Figure 6b). The non-galvanic condition provides cell endurance on the electrode surface that is suitable for cell growth, as obtained and observed by both the cell counter and SEM imaging. The structural change in Hs27 cells obtained through the cell counter was further confirmed by using SEM under non-galvanic and galvanic coupling conditions. Under non-galvanic conditions, cells were found to overlap, and were healthy (cf. Figure 7a). Conversely, under galvanic conditions (Figure 7b), cell remnants decreased and were found to retract as filopodia to form a ball-like structure. This squeeze of the cell into a ball-like structure was consistent with an apoptosis/necrosis process ${ }^{4}$.

Moreover, some cell remnants most likely associated with necrosis were observed near the ball, such as the Hs27 cells in Figure 7c. These cell remnants appeared as light and dark patches, which were previously reported to be protein agglomerates ${ }^{4}$. Hence, the cytotoxic 
activity of galvanically coupled Ti-Mg was responsible for the death of Hs27 cells based on these results.

\subsection{In vitro electrochemical testing}

To obtain information about the electrochemical processes occurring on the surface of the Ti-Mg galvanic coupling system, electrochemical tests were performed in a naturally aerated $0.1 \mathrm{M} \mathrm{NaCl}$ solution at room temperature under different polarization conditions. Since the electrical polarization of the galvanically coupled metals shifted to a potential close to those exhibited by spontaneously corroding $\mathrm{Mg}$, that is, consistent with the anodic behavior of this metal, it was hypothesized that the cytotoxic effects described in the previous section should mostly arise from a change in the chemical reactivity of the Ti sample as a result of the galvanic coupling condition. Therefore, a multiscale electrochemical characterization procedure was implemented to characterize the surface layers existing on $\mathrm{Ti}$ and their reactivity when the metal was polarized at $-0.8 \mathrm{~V}$, a potential value analogous to that experienced during Ti-Mg galvanic coupling ${ }^{28}$.

A preliminary characterization of the surface condition of the Ti sample was performed by EIS by recording the impedance spectra at its spontaneous OCP in the test electrolyte, as well as under a cathodic polarization analogous to that attained by the metal in the Ti-Mg galvanic coupling, namely, $-0.8 \mathrm{~V}$. The measured impedance spectra are shown in Figure 8 using both Nyquist and Bode diagrams, and the discrete points in the graphs are the measured data recorded in the experiments. The impedance diagrams displayed two time constants at both polarizations, one in the high-frequency range associated with the electrochemical double layer developed on the surface of the metallic material, while the low-frequency process could be associated with the passive layer formed on the surface of the alloys. Although the electrochemical behavior of the Ti surface could be described by the same model under both polarization conditions (i.e., characterized by the presence of an oxide layer on the surface of the metal), a decrease in the diameter of the semicircle in the Nyquist plot was readily observable when the metal was polarized at $-0.8 \mathrm{~V}$ compared to its open-circuit condition. An approximately one order of magnitude decrease in the resistance of the oxide layer occurred by applying this cathodic polarization.

A quantitative analysis of the impedance spectra was performed in terms of an electrical circuit (EC) representing the physicochemical processes occurring at the Ti sample. The twolayer model of the metal/oxide/solution interface usually employed to describe the passivity of titanium $^{31}$ was applied in this case for both polarization conditions, and good agreement 
between the measured data and the fitted spectra depicted as solid lines in Figure 8 was observed. The model consisted of two parallel constant phase elements (CPEs)/resistor couples, as displayed in the inset in Figure 8, $Q_{\mathrm{ox}} / R_{\mathrm{ox}}$ and $Q_{\mathrm{d} 1} / R_{\mathrm{ct}}$, dominating the impedance response in the low and high frequency ranges, respectively; this setup considers the corrosion of the passive titanium to be hindered by an oxide film that acts as a barrier layer. Then, the $R_{c t}$ and $Q_{d l}$ components describe the electrochemical reactions at the oxide layer/solution interface, whereas $R_{o x}$ and $Q_{o x}$ describe the resistance and capacitance of the compact oxide layers, respectively. Table 1 lists the values of the impedance parameters at the two polarizations under investigation.

CPEs were used instead of pure capacitances because of the nonideal capacitive response due to the distributed relaxation feature of the passive oxide films. Although exponential values $n$ smaller than 1 were always found for the CPEs, the values were equal to or greater than 0.8 , thus suggesting a rather smooth surface for the passive oxide layers. The capacitance values were derived from the CPE parameters using ${ }^{32}$ :

$$
C=\left(R^{1-n} Q\right)^{1 / n}
$$

It is usually considered that capacitance values are inversely proportional to the thickness of the corresponding surface layers by considering them as parallel-plate capacitors:

$$
C=\frac{\varepsilon \varepsilon_{0} A}{d}
$$

where $\varepsilon$ is the dielectric constant of the metal oxide, $\varepsilon_{0}$ is the dielectric permittivity of vacuum, $A$ is the effective area, and $d$ is the thickness of the oxide layer ${ }^{33}$. By comparing the capacitance values in Table 1, it can be proposed that the effect of cathodic polarization on the electrochemical behavior of the Ti sample was apparently related to a thinning of the oxide layer on the metal.

Next, the electrochemical reactivity of $\mathrm{Ti}$ in the Ti-Mg MGC was investigated using SECM operated in feedback mode with a $30 \mu$ m-diameter carbon microelectrode (C-ME) as the SECM probe and FcMeOH as the redox mediator. The small cylindrical cell created over the embedded Ti-Mg sample was filled with $4 \mathrm{~mL}$ of a solution containing $0.1 \mathrm{M} \mathrm{NaCl}+$ $2 \mathrm{mM}$ FcMeOH. The C-ME was initially placed at a $200 \mu \mathrm{m}$ vertical $(Z)$ distance from the central position on the surface of titanium, and it was polarized at $+0.60 \mathrm{~V}$ for the oxidation of $\mathrm{FcMeOH}$ to ferrocinium ions $\left(\mathrm{FeMeOH}^{+}\right)$at the tip under diffusion-limited conditions. Zapproach curves were recorded by progressively moving the tip toward the surface while monitoring the faradaic current at the tip. During these experiments, the Ti sample in the MGC was either left not polarized (i.e., at its OCP) or galvanically coupled to $\mathrm{Mg}$, and the Z-approach 
curves recorded for these two electrical conditions are displayed in Figure 9. In this graph, the abscissa values provided the normalized distance $L=d / a$, where $d$ is the $Z$ vertical distance between the SECM tip and the Ti strip, and $a$ is the radius of the SECM tip. Analogously, the ordinate values showed the normalized current $I=I_{\mathrm{d}} / I_{\infty}$, where $I_{\mathrm{d}}$ is the tip current measured at the gap distance $d$, and $I_{\infty}$ is the current measured in the bulk of the solution when the SECM tip is far from the surface of the sample.

When the Ti strip was electrically disconnected (i.e., OCP mode), the following behavior was observed. First, a steady current was recorded for the oxidation of FcMeOH to $\mathrm{FeMeOH}^{+}$at the C-ME for $L>4$, that is, when the C-ME was located far from the Ti surface. Further approaching the Ti surface with the C-ME $(L<4)$ led to a decay in the current values, a feature that is known as the negative feedback effect in SECM. This trend was due to the hindered diffusion of FcMeOH from the bulk electrolyte due to the proximity of the surface consisting of passive $\mathrm{TiO}_{2}$ film deposited on $\mathrm{Ti}$. The $\mathrm{TiO}_{2}$ film prevented the occurrence of an electron transfer reaction between the Ti metal and local environment that would be necessary for the regeneration of the redox mediator, as sketched in Figure 10a $\mathbf{a}^{8}$. This interpretation was supported by the SEM-EDX observations that showed the presence of a passive oxide film on the Ti surface (the results are shown in Figure 4a).

A very different trend was found in the tip approaching experiments as it moved toward the center of the Ti sample in the MGC while the two metals were electrically connected, effectively representing galvanic coupling conditions. The corresponding Z-approach curve is shown in Figure 9. Initially the same steady current behavior in the bulk of the electrolyte that was previously described in the case of the non-galvanic condition was observed. However, as the C-ME further approached the Ti surface starting at $L<4$, the tip current progressively increased. This behavior is known in $\mathrm{SECM}^{13}$ as the positive feedback effect. Since Ti acted as a cathode during galvanic coupling with $\mathrm{Mg}$, the abrupt increase in tip current was due to the enhanced availability of FcMeOH produced by the electroreduction of $\mathrm{FcMeOH}^{+}$ions on the Ti surface, as shown in Figure 10b. The change in the electrochemical behavior observed on Ti could be explained by the conversion of the passive film of $\mathrm{TiO}_{2}$ to a conductive oxyhydroxide film. The change in the total resistance of the surface film from $628 \mathrm{k} \Omega \mathrm{cm}^{2}$ under the non-galvanic condition to approximately $100 \mathrm{k} \Omega \mathrm{cm}^{2}$ after imposing a $-0.80 \mathrm{~V}$ cathodic polarization on the Ti sample (cf. Table 1), was in agreement with this explanation. The heterogeneous reaction induced by cathodic polarization resulted in the reduction of the $\mathrm{TiO}_{2}$ passive layer to a Ti hydroperoxo conductive film, which can be described as equation $3^{27,34}$. 


$$
\mathrm{TiO}_{2}+x \mathrm{H}_{\mathrm{aq}}^{+}+n \mathrm{e}^{-} \rightarrow \mathrm{TiO}_{2-x}(\mathrm{OH})_{x}
$$

The occurrence of the electron transfer reaction at the $\mathrm{Ti}$ oxide/electrolyte interface showed that the passivated $\mathrm{Ti}$ sample become electrochemically active when it was coupled with Mg. Notably, this was a relevant factor that may confer cell-killing characteristics on the Ti surface when coupled with Mg. The SECM operated in feedback mode proved that the electrochemical reactivity of the Ti surface changed from passive to conductive when it was galvanically coupled with Mg. Hence, other electrochemical reactions might occur on the Ti surface during galvanic coupling with Mg. Most likely, these electrochemical reactions could be either $\mathrm{H}_{2}$ evolution from water (equation 4) or the reduction of dissolved oxygen (equation 5), and both reactions could initiate local $\mathrm{pH}$ changes in the solution phase.

$$
\begin{gathered}
2 \mathrm{H}_{2} \mathrm{O}+2 \mathrm{e}^{-} \rightleftharpoons 2 \mathrm{OH}^{-}+\mathrm{H}_{2} \uparrow \\
\mathrm{O}_{2}+2 \mathrm{H}_{2} \mathrm{O}+4 \mathrm{e}^{-} \rightleftharpoons 4 \mathrm{OH}^{-}
\end{gathered}
$$

SECM operated in potentiometric mode was used to monitor the $\mathrm{pH}$ above the Ti surface using a $30 \mu \mathrm{m}$ diameter antimony microelectrode $\left(\mathrm{Sb} / \mathrm{Sb}_{2} \mathrm{O}_{3} \mathrm{ME}\right)$ as the measuring tip. The tipsample distance was set by recording a $Z$-approach curve while measuring the potential at the SECM tip with respect to a $\mathrm{Ag} / \mathrm{AgCl} /(3 \mathrm{M}, \mathrm{KCl})$ reference electrode. A jump in potential was observed when the tip touched the surface of the metal. That response was taken as the $0 \mu \mathrm{m}$ tip-sample distance. Then, the tip was retracted $50 \mu \mathrm{m}$ from the surface and subsequently moved parallel to the sample to a position located over the embedding resin at one side of the Ti strip. Line scans were recorded by moving the $\mathrm{Sb} / \mathrm{Sb}_{2} \mathrm{O}_{3} \mathrm{ME}$ along a 3,000 $\mu \mathrm{m}$ path toward the other side passing above the Ti surface in $50 \mu \mathrm{m}$ steps. Figure 11a shows a sketch of the potential sampling and recording made in each step, whereas Figure 11b shows the potentiometric SECM scan lines recorded while the Ti and Mg metals were either electrically disconnected or galvanically coupled.

When the Ti strip was electrically disconnected (i.e., OCP mode), the pH values were approximately 6.5 above both the resin and Ti surfaces. Indeed, this $\mathrm{pH}$ value matched the $\mathrm{pH}$ of the bulk solution. This observation implied that no electrochemical reactions occurred in the vicinity of the Ti sample due to the compact passive film deposited on the surface of the metal, effectively hindering the occurrence of electron transfer reactions with chemical species in the local environment.

The SECM experiment with a pH measuring tip was also performed over the Ti sample when galvanically coupled with Mg. The galvanic coupling of two dissimilar metals generated 
an electric field in the solution phase that affected the potential measured with the $\mathrm{pH}$-sensitive SECM tip, an effect that may cause misinterpretation of the potentiometric data ${ }^{35}$. To avoid the occurrence of this effect in our measurements, the Ti sample was electrically coupled with $\mathrm{Mg}$ for $15 \mathrm{~min}$, and the SECM line scan was measured immediately after the galvanic connection was interrupted. As shown in Figure 11b (red line), a pH close to 6.5 was recorded while the probe passed above the insulating resin on the left side of the embedded Ti sample. However, an abrupt $\mathrm{pH}$ increase to a value of 9.0 was recorded when the probe reached the Ti surface, and this $\mathrm{pH}$ value was maintained as long as the probe continued moving over the metal. A pH decrease to 6.5 occurred when the probe reached the resin on the right side of the embedded $\mathrm{Ti}$, and this was the same $\mathrm{pH}$ value observed over the resin on the left side. Indeed, the alkalinization observed above Ti resulted from the hydroxide ions yielded by the reduction of water (equation 3) or oxygen (equation 4). In this way, the occurrence of severe alkalinization to $\mathrm{pH}=9.0$ above $\mathrm{Ti}$ when galvanically coupled with $\mathrm{Mg}$ was demonstrated, a fact that may affect cytotoxicity.

\subsection{Effect of $\mathrm{pH}$ on the viability of Hs27 cells}

As observed in the SECM experiment, the $\mathrm{pH}$ value in the solution phase in direct contact with the Ti surface increased to 9.0 under galvanic conditions. Thus, the effect of such high $\mathrm{pH}$ values on the viability of Hs27 cells was investigated.

Trypan blue exclusion assays were performed for the two samples electrically disconnected, thus effectively at their corresponding open circuit potentials in the environment (non-galvanic condition, OCP mode), and for the galvanically-coupled metals that were electrically-connected at the rear of the mould containing the metal samples. A dramatic decrease in cell viability for the latter case was readily observable from the inspection of Figure 12. The obtained results revealed that the ratio of live/dead Hs27 cells positively correlated with $\mathrm{pH}$, as 96\%, 33\%, and 10\% living cells were found at $\mathrm{pH} 7.5$, 8.0, and 9.0, respectively. Experiments were also performed by varying the $\mathrm{pH}$ in the culture cell, and the resulting changes in cell viability of Hs27 were readily observable from the inspection of Figure 13 for cell viability study of Hs27 on the MGC in both the non-galvanic OCP and the galvanic-coupling modes.

At pH 7.5, Hs27 cells were found to be healthy, exhibiting a characteristic flat, elongated (spindle-shaped) morphology. The cells at $\mathrm{pH} 8.0$ were found to exhibit a similar morphology but decreased confluency compared to the cells at $\mathrm{pH}$ 7.5. This phenomenon was due to $\mathrm{pH} 8.0$ inhibiting cell proliferation. Importantly, at $\mathrm{pH}$ 9.0, the majority of the cells were found to be 
dead with structural deformation and squeezed to form ball-like structures. Moreover, scattered cell fragments were observed at $\mathrm{pH}$ 9.0. Therefore, it was confirmed that the high $\mathrm{pH}$ value reached on the Ti surface $(\mathrm{pH} \geq 9)$ during galvanic coupling with $\mathrm{Mg}$ effectively caused the death of Hs27 cells. Indeed, this observation may be valid to account for the observations made by Kim et al. in an investigation on the viability of MC3T3 cells in the presence of both plain Mg particles and galvanically coupled Mg-Ti particles ${ }^{3}$. Later, these authors also showed a cytotoxic effect of Mg-Ti particles on human osteosarcoma cells, indicating their potential application in cancer therapy ${ }^{4}$. However, they considered that the main factor responsible for cytotoxicity was the generation of ROS instead of the increase in $\mathrm{pH}$ because these particles only killed the cells in close proximity $(<1 \mathrm{~mm})$. However, as demonstrated in this work, the local $\mathrm{pH}$ at the Ti surface, under galvanic coupling with $\mathrm{Mg}$, greatly differed from the bulk $\mathrm{pH}$ in the electrolytic environment, which could be the reason why the Ti-Mg particles exerted fatal effects on the cells in close vicinity. Therefore, the effect of high alkaline $\mathrm{pH}$ values on cell viability should not be underestimated.

\subsection{Quantification of intracellular ROS}

The cytotoxicity of Ti-Mg under galvanic conditions might also stem from the increase in generated ROS content. When ROS, including superoxides, hydroxyl radicals, and singlet oxygen, are generated in high amounts, they cause serious damage to cells and even cell death ${ }^{36}$. Thus, the amount of generated ROS content was investigated under both galvanic and nongalvanic conditions. The same amount of Hs27 cells was placed on MGCs and incubated under the above conditions for $48 \mathrm{~h}$ in both the non-galvanic OCP and the galvanically coupled modes. Trypan blue exclusion testing determined $87 \%$ and $17 \%$ of living Hs27 cells under the non-galvanic and galvanic conditions, respectively (cf. Figure 14).

Additionally, intracellular ROS formation was examined in both non-galvanic OCP and galvanically coupled modes. Figure 15a shows the gating strategy and fluorescence intensities of CellROX Deep Red reagent-stained intracellular ROS. Importantly, the obtained data revealed that in galvanic mode, ROS generation increased to approximately $260 \%$ compared to that under the non-galvanic condition (see Figure 15b). Given the biocompatible nature of the MGC in the non-galvanic OCP mode, the Ti-Mg coupling could be responsible for the induction of external oxidative stress through the formation of ROS species through intermediate oxygen reduction reactions according to equations (6)-(9):

$$
\mathrm{O}_{2}+\mathrm{e}^{-} \rightleftharpoons \mathrm{O}_{2}^{-}
$$




$$
\mathrm{O}_{2}+\mathrm{e}^{-}+2 \mathrm{H}^{+} \rightleftharpoons \mathrm{H}_{2} \mathrm{O}_{2}
$$

$$
\mathrm{H}_{2} \mathrm{O}_{2}+\mathrm{e}^{-}+\mathrm{H}^{+} \rightleftharpoons \mathrm{OH}+\mathrm{H}_{2} \mathrm{O}
$$

$$
\mathrm{OH}+\mathrm{e}^{-}+\mathrm{H}^{+} \rightleftharpoons \mathrm{H}_{2} \mathrm{O}
$$

Increased oxidative stress was plausibly the main reason for cell death, as reported earlier $^{36-39}$. Therefore, it was shown that the galvanic coupling of $\mathrm{Ti}$ with $\mathrm{Mg}$ resulted in an increased concentration of ROS compared to the non-galvanic condition (approximately 2.6 times), which was another reason for the cytotoxic behavior of Ti-Mg galvanic systems. The obtained results may also explain the observations by Hou et al. ${ }^{40}$ in which they reported reduced bone tissue ingrowth in addition to increased corrosion rates for $\mathrm{Mg}$ when examining the corrosion of Mg coimplanted with Ti in Sprague-Dawley rat femurs.

\section{Conclusion}

Mere comparison of the standard reduction potentials of Ti and Mg has led to the usual assumption that the probability of galvanic corrosion in Ti-Mg alloys when inserted in an electrolyte should be minimal and that the cytotoxic effect of galvanically coupled Mg-Ti particles would be mainly due to $\mathrm{Mg}$ and its higher corrosion rate in the presence of $\mathrm{Ti}$. However, a combined in vitro electrochemical investigation and in vivo cell culture approach performed in this work showed the role of $\mathrm{Ti}$ in the cytotoxic effect of Ti-Mg systems. That is, by galvanic coupling with Mg, the previously passive and insulating oxide layer present on $\mathrm{Ti}$ became electrochemically active to undergo heterogeneous electron transfer reactions, as revealed using amperometric SECM. The electrochemical activation of the Ti surface led to enhanced generation of ROS and the production of a highly alkaline environment as it was quantified with potentiometric SECM. Partial reduction of the $\mathrm{TiO}_{2}$ layer to a hydroxoperoxo film has been proposed to account for the reported electrochemical observations.

The viability of Hs27 cells has been shown to decrease significantly when $\mathrm{Ti}$ is galvanically coupled with Mg. The occurrence of cytotoxic effects in the galvanically coupled Ti-Mg system has been successfully characterized in terms of three distinguishable processes: the electrochemical reactivity of $\mathrm{Ti}$ when galvanically coupled with $\mathrm{Mg}$, the increased ROS generation in Ti-Mg galvanic cells, and the increase in $\mathrm{pH}$ above $\mathrm{Ti}$ due to the onset of electrochemical reactions. As a result, the Ti surface itself became electrochemically active and participated in heterogeneous electron transfer reactions with chemical species in the surrounding media, causing lethal effects on surrounding cells. 


\section{Funding sources}

This research was carried out under the project CEITEC 2020 (LQ1601) with financial support from the Ministry of Education, Youth and Sports of the Czech Republic under the National Sustainability Program II. Additionally, it was supported by ERDF "Multidisciplinary research to increase application potential of nanomaterials in agricultural practice" (No. CZ.02.1.01/0.0/0.0/16_025/0007314). Furthermore, the support from the Hungarian Research Grant NFKI Nr. 125244 (Budapest, Hungary) is acknowledged. The authors also gratefully acknowledge financial support from ERASMUS+ Staff Mobility from the European Commission.

\section{Data availability}

The data that support the plots within this paper and other findings of this study are available from the corresponding author upon reasonable request.

\section{Declaration of Competing Interest}

The authors declare that they have no known competing financial interests or personal relationships that could have appeared to influence the work reported in this paper.

\section{References}

(1) Geetha, M.; Singh, A. K.; Asokamani, R.; Gogia, A. K. Ti based biomaterials, the ultimate choice for orthopaedic implants - A review. Prog. Mater. Sci. 2009, 54 (3), 397-425, DOI: 10.1016/j.pmatsci.2008.06.004.

(2) Staiger, M. P.; Pietak, A. M.; Huadmai, J.; Dias, G. Magnesium and its alloys as orthopedic biomaterials: A review. Biomaterials 2006, 27 (9), 1728-1734, DOI: 10.1016/j.biomaterials.2005.10.003.

(3) Kim, J.; Gilbert, J. L. Cytotoxic effect of galvanically coupled magnesium-titanium particles. Acta Biomater. 2016, 30, 368-377, DOI: 10.1016/j.actbio.2015.11.030.

(4) Kim, J.; Gilbert, J. L. In vitro cytotoxicity of galvanically coupled magnesium-titanium particles on human osteosarcoma SAOS2 cells: A potential cancer therapy. J. Biomed. Mater. Res. Part B 2019, 107 (1), 178-189, DOI: 10.1002/jbm.b.34109. 
(5) Lemire, J. A.; Harrison, J. J.; Turner, R. J. Antimicrobial activity of metals: mechanisms, molecular targets and applications. Nat. Rev. Microbiol. 2013, 11 (6), 371-384, DOI: 10.1038/nrmicro3028.

(6) Thull, R. Tissue-implant interaction, in: Metals as Biomaterials Wiley: New York, 1998.

(7) Worch, H. Special thin organic coatings, in: Metals as Biomaterials, Wiely: New York, 1998.

(8) Asserghine, A.; Filotas, D.; Nagy, L.; Nagy, G. Scanning electrochemical microscopy investigation of the rate of formation of a passivating TiO2 layer on a Ti G4 dental implant. Electrochem. Commun. 2017, 83, 33-35, DOI: 10.1016/j.elecom.2017.08.018.

(9) Asserghine, A.; Filotas, D.; Nemeth, B.; Nagy, L.; Nagy, G. Potentiometric scanning electrochemical microscopy for monitoring the $\mathrm{pH}$ distribution during the self-healing of passive titanium dioxide layer on titanium dental root implant exposed to physiological buffered (PBS) medium. Electrochem. Commun. 2018, 95, 1-4, DOI: 10.1016/j.elecom.2018.08.008.

(10) Asserghine, A.; Medvidovic-Kosanovic, M.; Nagy, L.; Nagy, G. In situ monitoring of the transpassivation and repassivation of the passive film on nitinol biomaterial by scanning electrochemical microscopy. Electrochem. Commun. 2019, 107, 1-6, DOI: 10.1016/j.elecom.2019.106539.

(11) Ehrensberger, M. T.; Tobias, M. E.; Nodzo, S. R.; Hansen, L. A.; Luke-Marshall, N. R.; Cole, R. F.; Wild, L. M.; Campagnari, A. A. Cathodic voltage-controlled electrical stimulation of titanium implants as treatment for methicillin-resistant Staphylococcus aureus periprosthetic infections. Biomaterials 2015, 41, 97-105, DOI: 10.1016/j.biomaterials.2014.11.013.

(12) Payne, N. A.; Stephens, L. I.; Mauzeroll, J. The Application of Scanning Electrochemical Microscopy to Corrosion Research. Corrosion 2017, 73 (7), 759-780, DOI: 10.5006/2354.

(13) Polcari, D.; Dauphin-Ducharme, P.; Mauzeroll, J. Scanning Electrochemical Microscopy: A Comprehensive Review of Experimental Parameters from 1989 to 2015. Chem. Rev. 2016, 116 (22), 13234-13278, DOI: 10.1021/acs.chemrev.6b00067.

(14) Thomas, S.; Izquierdo, J.; Birbilis, N.; Souto, R. M. Possibilities and Limitations of Scanning Electrochemical Microscopy of Mg and Mg Alloys. Corrosion 2015, 71 (2), 171-183, DOI: $10.5006 / 1483$.

(15) Dauphin-Ducharme, P.; Kuss, C.; Rossouw, D.; Payne, N. A.; Danis, L.; Botton, G. A.; Mauzeroll, J. Corrosion Product Formation Monitored Using the Feedback Mode of Scanning Electrochemical Microscopy with Carbon Microelectrodes. J. Electrochem. Soc. 2015, 162 (12), C677-C683, DOI: 10.1149/2.0701512jes. 
(16) Filotas, D.; Fernandez-Perez, B. M.; Nagy, L.; Nagy, G.; Souto, R. M. Multi-barrel electrodes containing an internal micro-reference for the improved visualization of galvanic corrosion processes in magnesium-based materials using potentiometric scanning electrochemical microscopy. Sens. Actuator B-Chem. 2019, 296, 1-10, DOI: 10.1016/j.snb.2019.126625.

(17) Izquierdo, J.; Fernandez-Perez, B. M.; Filotas, D.; Ori, Z.; Kiss, A.; Martin-Gomez, R. T.; Nagy, L.; Nagy, G.; Souto, R. M. Imaging of Concentration Distributions and Hydrogen Evolution on Corroding Magnesium Exposed to Aqueous Environments Using Scanning Electrochemical Microscopy. Electroanalysis 2016, 28 (10), 2354-2366, DOI: 10.1002/elan.201600265.

(18) Jamali, S. S.; Moulton, S. E.; Tallman, D. E.; Forsyth, M.; Weber, J.; Wallace, G. G. Evaluating the corrosion behaviour of Magnesium alloy in simulated biological fluid by using SECM to detect hydrogen evolution. Electrochim. Acta 2015, 152, 294-301, DOI: 10.1016/j.electacta.2014.11.012.

(19) Salleh, S. H.; Thomas, S.; Yuwono, J. A.; Venkatesan, K.; Birbilis, N. Enhanced hydrogen evolution on $\mathrm{Mg}(\mathrm{OH})(2)$ covered $\mathrm{Mg}$ surfaces. Electrochim. Acta 2015, 161, 144-152, DOI: 10.1016/j.electacta.2015.02.079.

(20) Tefashe, U. M.; Snowden, M. E.; Ducharme, P. D.; Danaie, M.; Botton, G. A.; Mauzeroll, J. Local flux of hydrogen from magnesium alloy corrosion investigated by scanning electrochemical microscopy. J. Electroanal. Chem. 2014, 720, 121-127, DOI: 10.1016/j.jelechem.2014.03.002.

(21) Dauphin-Ducharme, P.; Asmussen, R. M.; Shoesmith, D. W.; Mauzeroll, J. In-situ Mg2+ release monitored during magnesium alloy corrosion. J. Electroanal. Chem. 2015, 736, 61-68, DOI: 10.1016/j.jelechem.2014.10.030.

(22) Izquierdo, J.; Kiss, A.; Santana, J. J.; Nagy, L.; Bitter, I.; Isaacs, H. S.; Nagy, G.; Souto, R. M. Development of Mg2+ Ion-Selective Microelectrodes for Potentiometric Scanning Electrochemical Microscopy Monitoring of Galvanic Corrosion Processes. J. Electrochem. Soc. 2013, 160 (9), C451C459, DOI: 10.1149/2.001310jes.

(23) Pust, S. E.; Scharnweber, D.; Kirchner, C. N.; Wittstock, G. Heterogeneous distribution of reactivity on metallic biomaterials: Scanning probe microscopy studies of the biphasic Ti alloy Ti6Al4V. Adv. Mater. 2007, 19 (6), 878-882, DOI: 10.1002/adma.200601446.

(24) Zhu, R. K.; Nowierski, C.; Ding, Z. F.; Noel, J. J.; Shoesmith, D. W. Insights into grain structures and their reactivity on grade-2 Ti alloy surfaces by scanning electrochemical microscopy. Chem. Mat. 2007, 19 (10), 2533-2543, DOI: 10.1021/cm070023d. 
(25) Casillas, N.; Charlebois, S. J.; Smyrl, W. H.; White, H. S. Scanning Electrochemical Microscopy of Precursor Sites for Pitting Corrosion on Titanium. J. Electrochem. Soc. 1993, 140 (9), L142-L145, DOI: 10.1149/1.2220897.

(26) Hannan, R. T.; Peirce, S. M.; Barker, T. H. Fibroblasts: Diverse Cells Critical to Biomaterials Integration. ACS Biomaterials Science \& Engineering 2018, 4 (4), 1223-1232, DOI: 10.1021/acsbiomaterials.7b00244.

(27) Asserghine, A.; Medvidovic-Kosanovic, M.; Nagy, L.; Souto, R. M.; Nagy, G. A study of the electrochemical reactivity of titanium under cathodic polarization by means of combined feedback and redox competition modes of scanning electrochemical microscopy. Sens. Actuator B-Chem. 2020, 320, 1-11, DOI: 10.1016/j.snb.2020.128339.

(28) Gilbert, J. L. Electrochemical coupling of metallic biomaterial implants for biological effect. 2015.

(29) Csoka, B.; Kovacs, B.; Nagy, G. Investigation of concentration profiles inside operating biocatalytic sensors with scanning electrochemical microscopy (SECM). Biosens. Bioelectron. 2003, 18 (2-3), 141-149, DOI: 10.1016/s0956-5663(02)00167-7.

(30) Horrocks, B. R.; Mirkin, M. V.; Pierce, D. T.; Bard, A. J.; Nagy, G.; Toth, K. Scanning electrochemical microscopy. 19. Ion-selective potentiometric microscopy. Anal. Chem. 1993, 65 (9), 1213-1224, DOI: 10.1021/ac00057a019.

(31) Pan, J.; Thierry, D.; Leygraf, C. Electrochemical impedance spectroscopy study of the passive oxide film on titanium for implant application. Electrochim. Acta 1996, 41 (7-8), 1143-1153, DOI: 10.1016/0013-4686(95)00465-3.

(32) Wang, B. L.; Zheng, Y. F.; Zhao, L. C. Effects of Hf content and immersion time on electrochemical behavior of biomedical Ti-22Nb-xHf alloys in $0.9 \% \mathrm{NaCl}$ solution. Mater. Corros. 2009, 60 (5), 330335, DOI: 10.1002/maco.200805120.

(33) Pan, J.; Thierry, D.; Leygraf, C. Hydrogen peroxide toward enhanced oxide growth on titanium in PBS solution: Blue coloration and clinical relevance. J. Biomed. Mater. Res. 1996, 30 (3), 393-402.

(34) Macak, J. M.; Tsuchiya, H.; Ghicov, A.; Yasuda, K.; Hahn, R.; Bauer, S.; Schmuki, P. TiO2 nanotubes: Self-organized electrochemical formation, properties and applications. Curr. Opin. Solid State Mat. Sci. 2007, 11 (1-2), 3-18, DOI: 10.1016/j.cossms.2007.08.004. 
(35) Kiss, A.; Filotas, D.; Souto, R. M.; Nagy, G. The effect of electric field on potentiometric Scanning Electrochemical Microscopic imaging. Electrochem. Commun. 2017, 77, 138-141, DOI: 10.1016/j.elecom.2017.03.011.

(36) Pelicano, H.; Carney, D.; Huang, P. ROS stress in cancer cells and therapeutic implications. Drug Resist. Updates 2004, 7 (2), 97-110, DOI: 10.1016/j.drup.2004.01.004.

(37) Booth, D. M.; Murphy, J. A.; Mukherjee, R.; Awais, M.; Neoptolemos, J. P.; Gerasimenko, O. V.; Tepikin, A. V.; Petersen, O. H.; Sutton, R.; Criddle, D. N. Reactive Oxygen Species Induced by Bile Acid Induce Apoptosis and Protect Against Necrosis in Pancreatic Acinar Cells. Gastroenterology 2011, 140 (7), 2116-2125, DOI: 10.1053/j.gastro.2011.02.054.

(38) Cho, K. S.; Lee, E. H.; Choi, J. S.; Joo, C. K. Reactive oxygen species-induced apoptosis and necrosis in bovine corneal endothelial cells. Invest. Ophthalmol. Vis. Sci. 1999, 40 (5), 911-919.

(39) Higuchi, M.; Honda, T.; Proske, R. J.; Yeh, E. T. H. Regulation of reactive oxygen species-induced apoptosis and necrosis by caspase 3-like proteases. Oncogene 1998, 17 (21), 2753-2760, DOI: 10.1038/sj.onc.1202211.

(40) Hou, P.; Han, P.; Zhao, C. L.; Wu, H. L.; Ni, J. H.; Zhang, S. X.; Liu, J. Y.; Zhang, Y. Z.; Xu, H. D.; Cheng, P. F.; Liu, S.; Zheng, Y. F.; Zhang, X. N.; Chai, Y. M. Accelerating Corrosion of Pure Magnesium Co-implanted with Titanium in Vivo. Sci Rep 2017, 7, 1-10, DOI: 10.1038/srep41924.

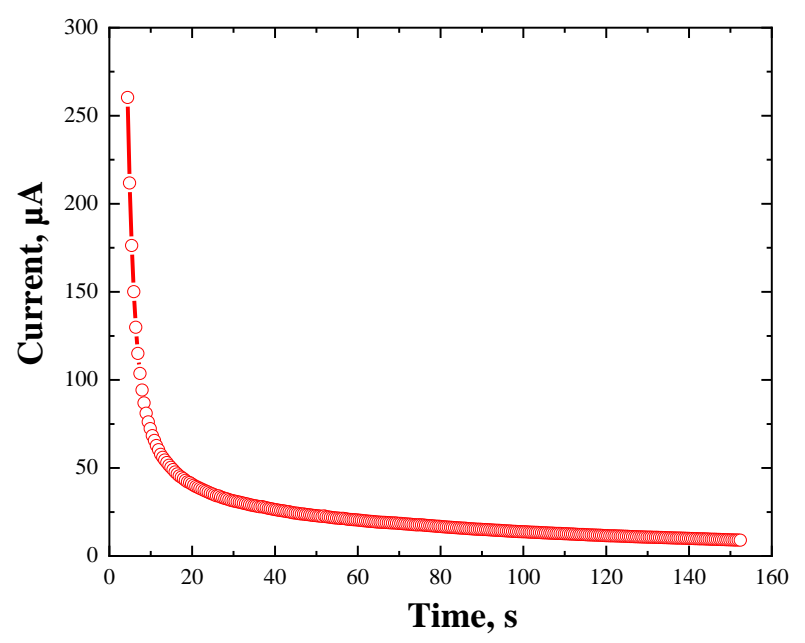

Figure 1. Current transient recorded on a freshly polished titanium immersed in $0.1 \mathrm{M} \mathrm{NaCl}$ solution upon the application of a potentiostatic pulse at $+2.00 \mathrm{~V}$ vs. $\mathrm{Ag} / \mathrm{AgCl} /(3 \mathrm{M}) \mathrm{KCl}$. 


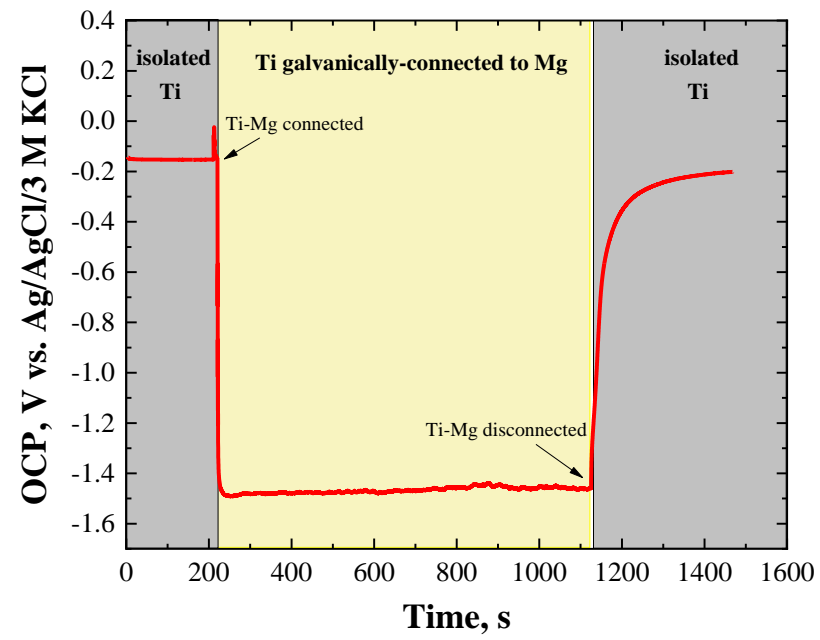

Figure 2. OCP measurement of a pre-treated titanium immersed in a naturally aerated $0.1 \mathrm{M} \mathrm{NaCl}$ solution. The metal was initially maintained electrically disconnected from $\mathrm{Mg}$, thus effectively at is spontaneous open circuit potential for $200 \mathrm{~s}$. Then, galvanic connection with Mg was performed at the rear of the mould containing the model Mg-Al system for 900 s. Finally, the galvanic coupling was stopped, and the titanium sample was left unpolarised in the system for the remaining of the experiment.

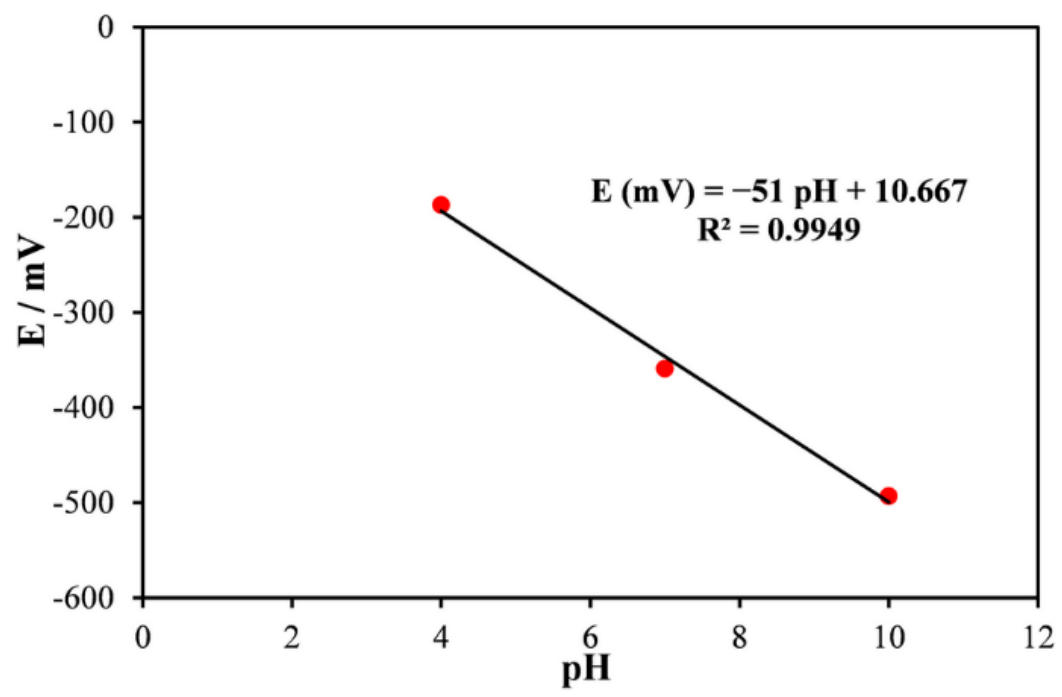

Figure 3. Calibration curve of the antimony microelectrode used as tip for potentiometric SECM operation. 

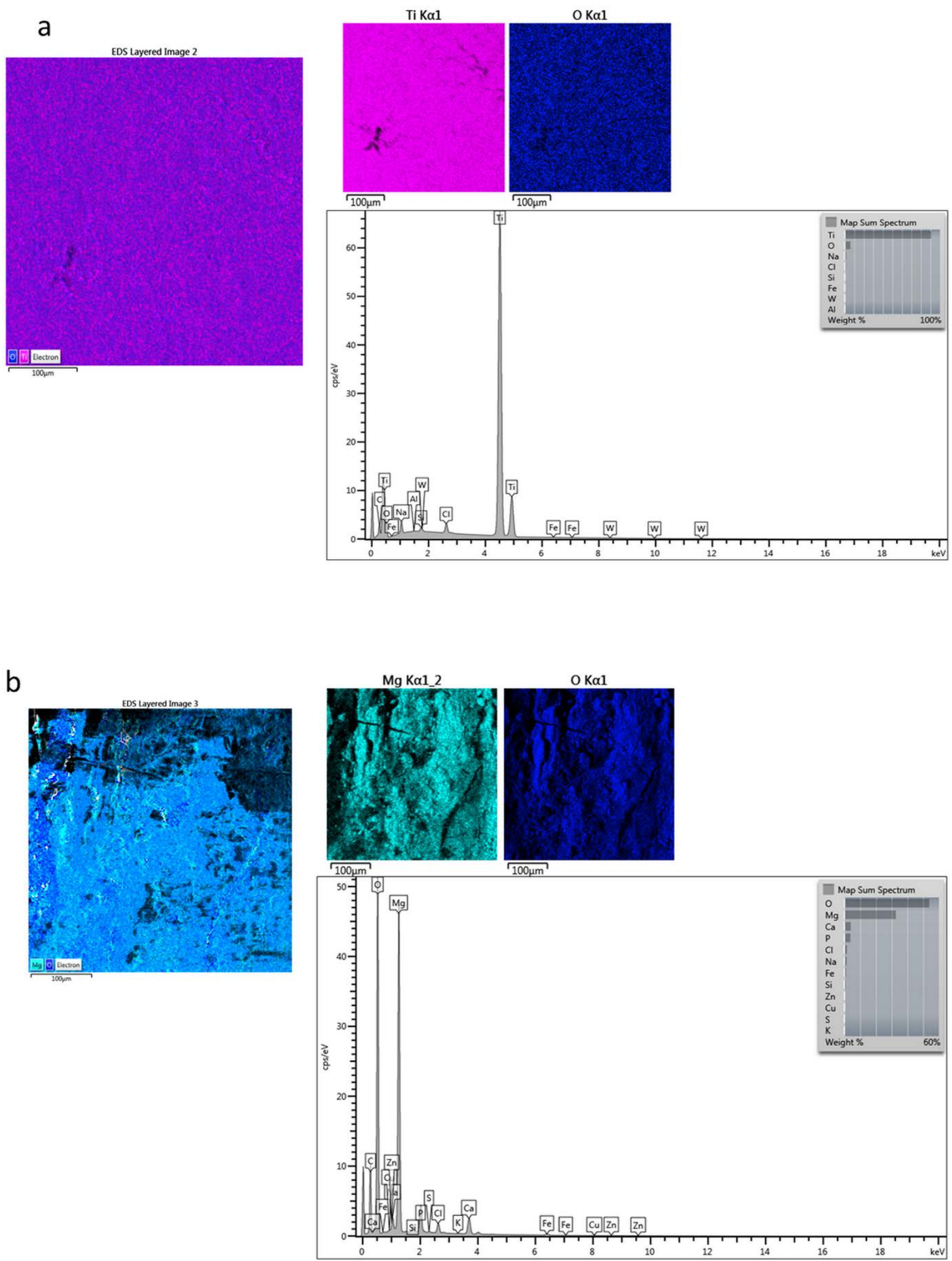

Figure 4. EDX surface mapping and elemental analysis of: (a) the Ti surface, and (b) the Mg surface. 

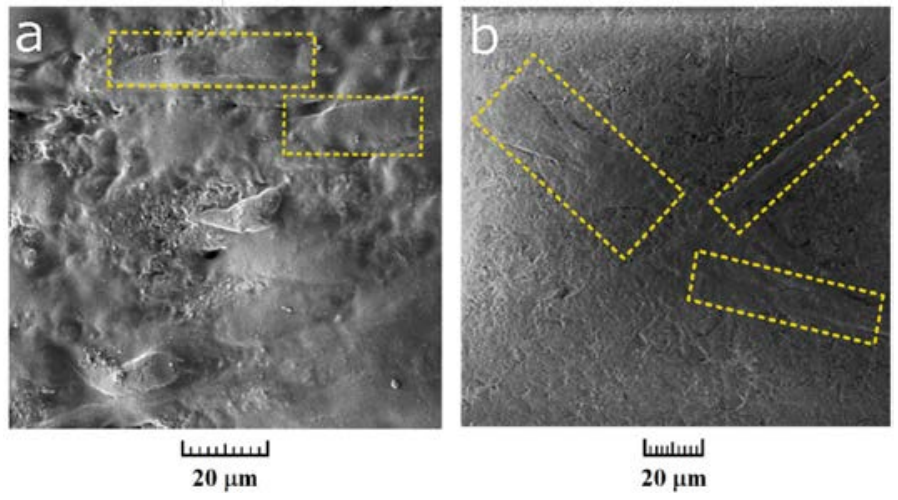

Figure 5. Cell culturing and cell viability of Hs27 cells: a) occurrence of healthy Hs27 cells on the carbon stub imaged by cryo-SEM (some of Hs27 cells which are well-visible are marked), and b) occurrence of healthy Hs27 cells on the MGC in OCP mode (non-galvanic coupling) conditions imaged by SEM (some of Hs27 cells which are well-visible are marked). Accelerating voltage: $1.0 \mathrm{kV}$ emission energy.
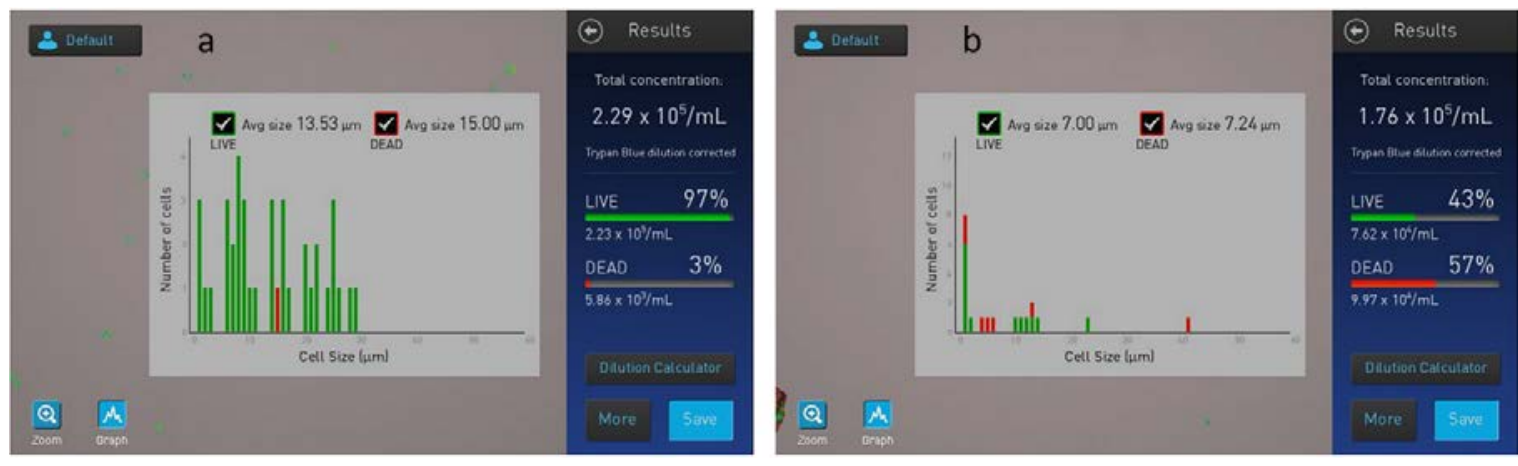

Figure 6. Trypan blue exclusion cell viability study of Hs27 on the MGC under: (a) non-galvanic OCP mode, and (b) galvanic-coupling mode.
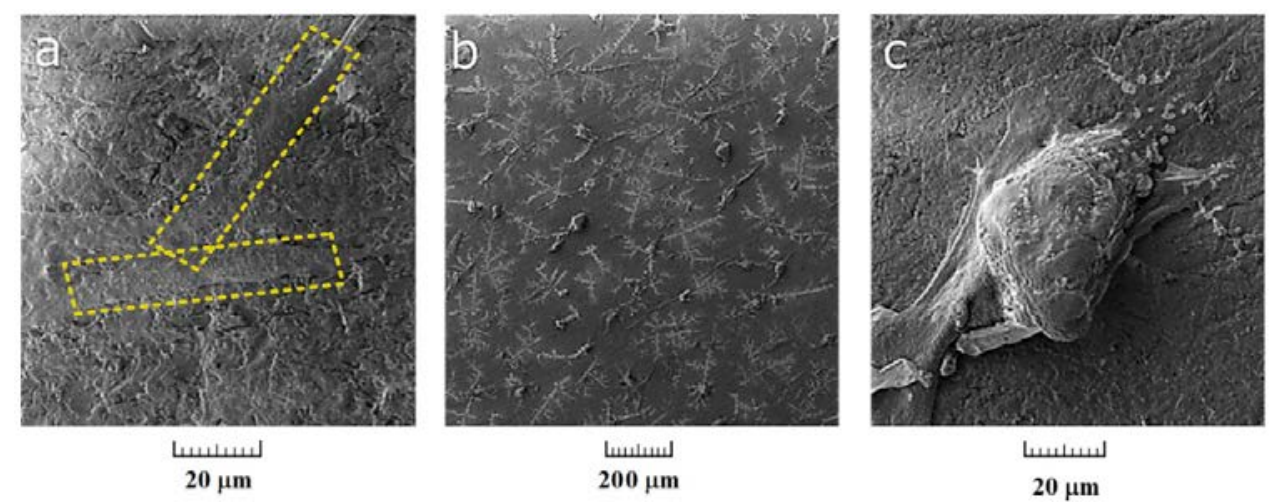

Figure 7. Effect of galvanic coupling between $\mathrm{Ti}$ and $\mathrm{Mg}$ on cell culturing and the cell viability of Hs27 cells: a) SEM image of Hs27 cells on Ti-Mg MGC in OCP mode (non-galvanic), the well-visible healthy Hs27 cells are marked; b) and c) images of Hs27 cells on Ti-Mg MGC under galvanic coupling mode. The image in b) provides a surface overview of deformed Hs27 on the MGC with remnants, whereas c) presents the structure of a deformed Hs27 cell. 

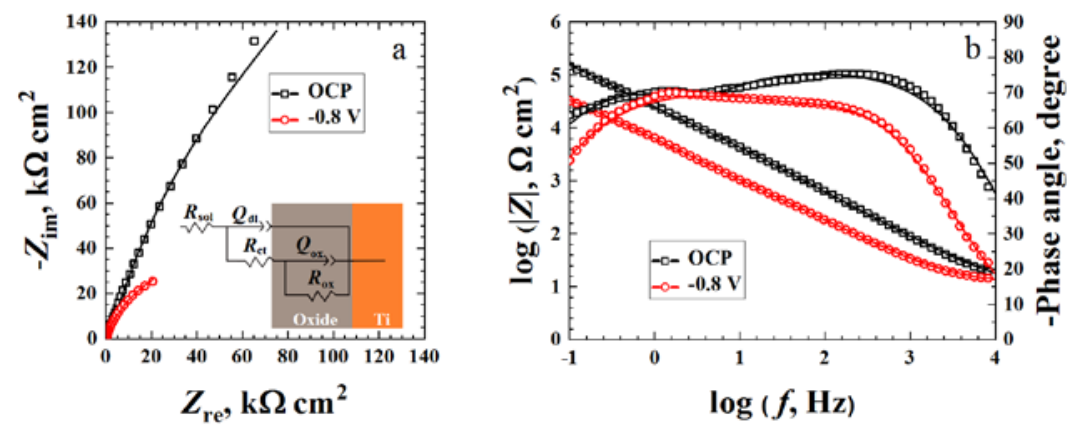

Figure 8. (a) Nyquist and (b) Bode diagrams of an oxide-covered Ti strip immersed in a naturally aerated $0.1 \mathrm{M} \mathrm{NaCl}$ solution for the potential values indicated in the plots. The solid lines and discrete points correspond to the fitted and measured data, respectively.

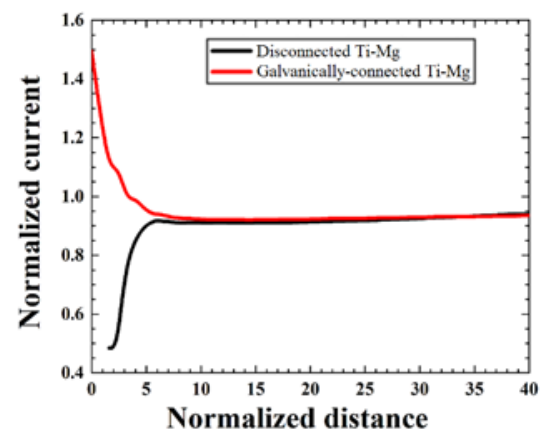

Figure 9. SECM Z-approach curves for the oxide-covered Ti surface in the MGC during immersion in $0.1 \mathrm{M} \mathrm{NaCl}+2 \mathrm{mM}$ FcMeOH . Electrical condition of the Ti strip: (black) non-galvanic condition, effectively at its spontaneous open-circuit potential in the electrolyte, and (red) galvanically coupled to $\mathrm{Mg}$. The C-ME is polarized at $+0.6 \mathrm{~V}$ for the oxidation of $\mathrm{FcMeOH}$ to ferrocinium ions $\left(\mathrm{FcMeOH}^{+}\right)$.
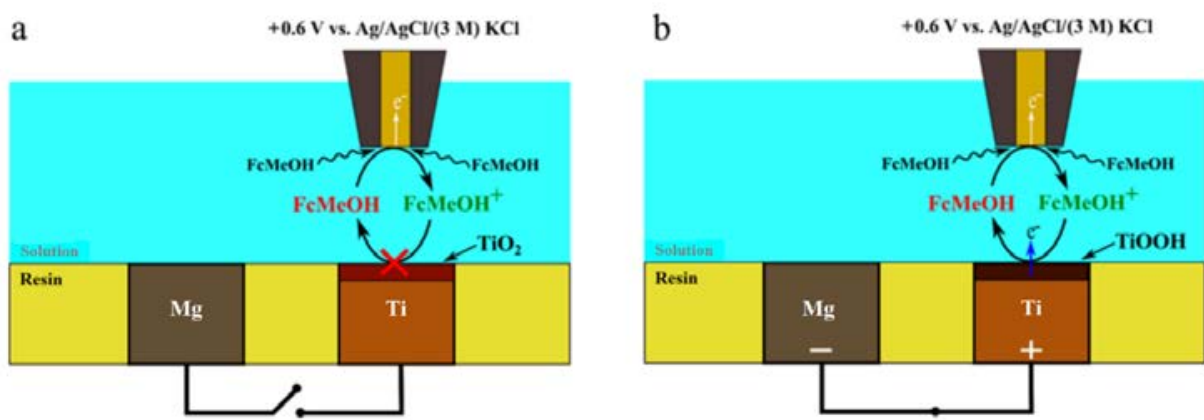

Figure 10. Schematic representations of the feedback responses observed using amperometric SECM on the oxide-covered Ti surface in the MGC during immersion in $0.1 \mathrm{M} \mathrm{NaCl}+2 \mathrm{mM} \mathrm{FcMeOH}$. (a) Negative feedback mode mechanism occurring on the Ti surface of the MGC when the metal is electrically disconnected from Mg (OCP mode); and (b) positive feedback mode observed on the Ti surface of the MGC under galvanic conditions (electrically connected). The C-ME is polarized at $+0.6 \mathrm{~V}$ for the diffusion-controlled oxidation of $\mathrm{FcMeOH}$ to ferrocinium ions $\left(\mathrm{FcMeOH}^{+}\right)$. 

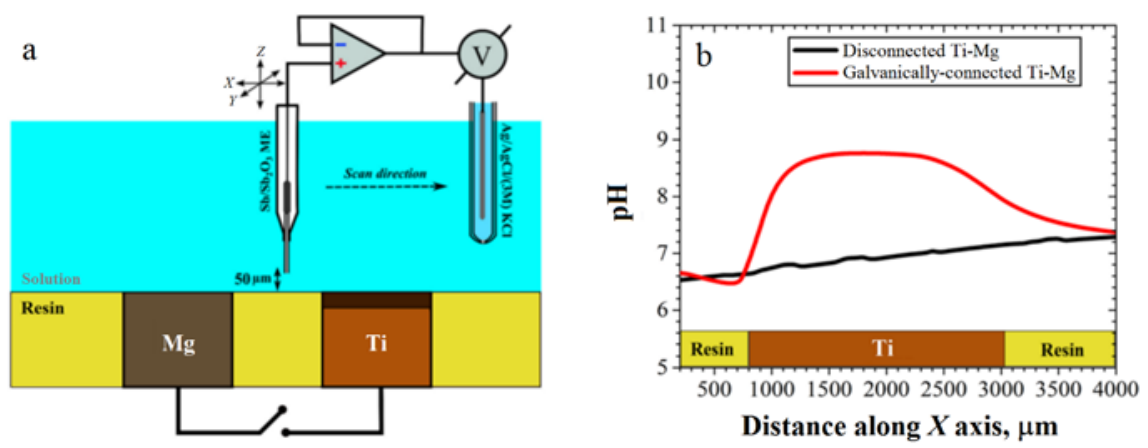

Figure 11. SECM investigation of the oxide-covered Ti sample in the MGC immersed in a $0.1 \mathrm{M} \mathrm{NaCl}$ solution using an $\mathrm{Sb} / \mathrm{Sb}_{2} \mathrm{O}_{3} \mathrm{ME}$ for potentiometric operation. (a) Schematic representation of the line scan measurement with a pH-sensitive electrode on the Ti surface of the MGC. (b) Potentiometric SECM scan lines recorded by the $\mathrm{Sb} / \mathrm{Sb}_{2} \mathrm{O}_{3} \mathrm{ME}$ when the Ti strip in the MGC was either electrically disconnected (OCP condition; black line) or galvanically coupled to Mg (galvanic condition; red line).
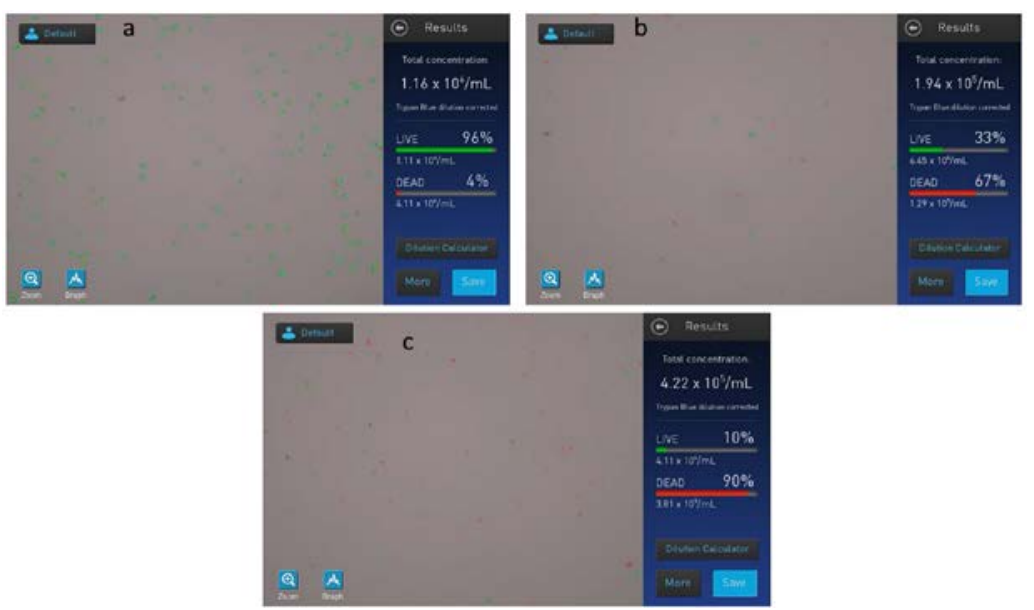

Figure 12. Viability of Hs27 cells at different $\mathrm{pH}$ values: (a) $\mathrm{pH}$ 7.5, (b) $\mathrm{pH}$ 8.0, and (c) $\mathrm{pH} 9.0$ determined by Trypan blue exclusion.
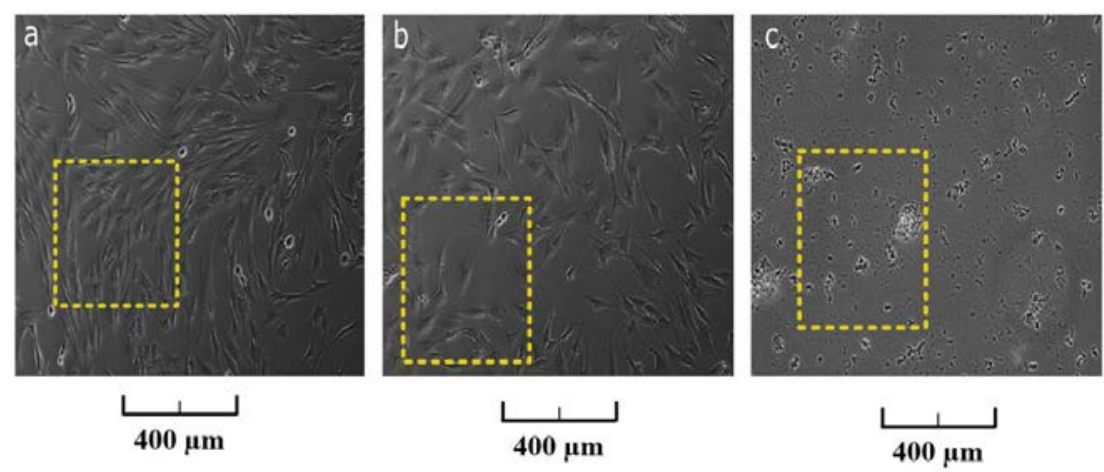

Figure 13. Optical microscopy images of Hs-27 cells cultured in tissue culture plates and maintained at different pH values: (a) pH 7.5 (control), (b) $\mathrm{pH}$ 8, and (c) pH 9. The marked areas show that in $\mathrm{pH}$ 7.5 the majority of the Hs27 are live and healthy, and at pH 8 even though the Hs27 cells are healthy some disruption are also formed. These disrupted areas increased at $\mathrm{pH} 9$. 


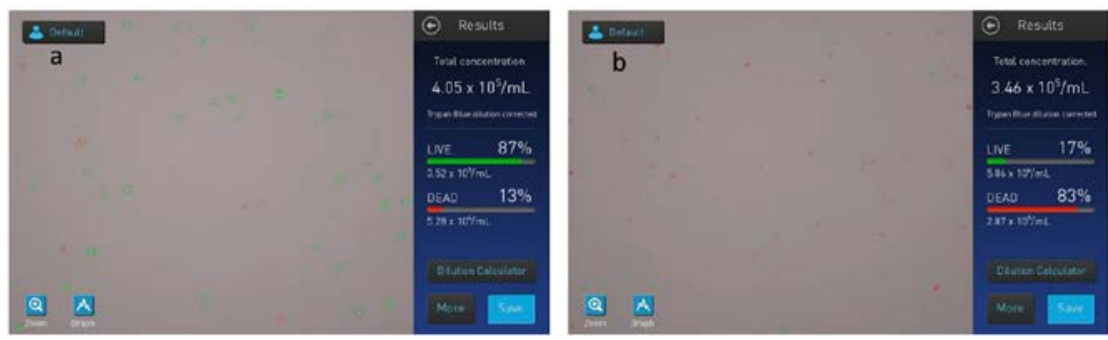

Figure 14. Trypan blue exclusion cell viability study of Hs27 on MGC at: (a) non-galvanic OCP mode, and (b) galvanic coupling mode.
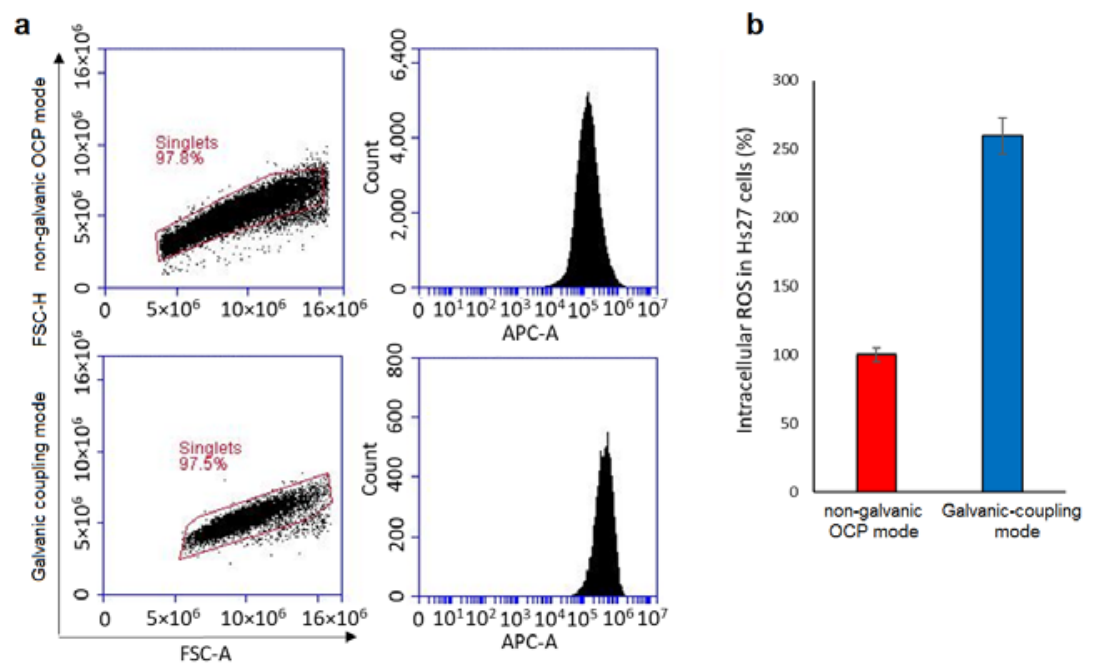

Figure 15. Flow cytometry analysis of intracellular ROS formation in Hs27 cells cultured on the MGC for $48 \mathrm{~h}$. (a) Gating strategy showing the singlet populations analyzed for ROS content (left) and fluorescence intensities of ROS analyzed in the APC channel. (b) Bar graph showing a marked ROS amount in Hs27 cells cultured on the MGC under galvanic coupling mode.

Table 1. Impedance parameters of oxide covered titanium immersed in $0.1 \mathrm{M} \mathrm{NaCl}$ solution without and with galvanic coupling to $\mathrm{Mg}$.

\begin{tabular}{|c|c|c|}
\hline & \multicolumn{2}{|c|}{ Electrical condition of the oxide covered titanium in the MGC } \\
\hline & $\begin{array}{l}\text { Without electrical connection } \\
\text { (OCP mode) }\end{array}$ & $\begin{array}{l}\text { Galvanic coupled with Mg } \\
\text { (galvanic mode) }\end{array}$ \\
\hline$R_{\mathrm{s}}\left(\Omega \mathrm{cm}^{2}\right)$ & 10.6 & 11.6 \\
\hline$R_{\mathrm{ct}}\left(\mathrm{k} \Omega \mathrm{cm}^{2}\right)$ & 2.13 & 0.0378 \\
\hline $\mathrm{CPE}_{\mathrm{dl}}\left(\mu \mathrm{S} \mathrm{s} \mathrm{s}^{n-1} \mathrm{~cm}^{-2}\right)$ & 22.8 & 189 \\
\hline$n_{\mathrm{dl}}$ & 0.916 & 0.872 \\
\hline$C_{\mathrm{dl}}\left(\mu \mathrm{F} \mathrm{s}^{n-1} \mathrm{~cm}^{-2}\right)$ & 17.3 & 91.5 \\
\hline$R_{\text {ox }}\left(\mathrm{k} \Omega \mathrm{cm}^{2}\right)$ & 626 & 93.7 \\
\hline $\mathrm{CPE}_{\mathrm{ox}}\left(\mu \mathrm{S} \mathrm{s} \mathrm{s}^{n-1} \mathrm{~cm}^{-2}\right)$ & 8.72 & 35.9 \\
\hline$n_{\text {ox }}$ & 0.840 & 0.796 \\
\hline$C_{o x}\left(\mu \mathrm{F} \mathrm{s}^{n-1} \mathrm{~cm}^{-2}\right)$ & 12.0 & 49.0 \\
\hline
\end{tabular}


